\title{
Liver Metastases in Newly Diagnosed Pancreatic Ductal Adenocarcinoma: A Population Based Analysis
}

Guoyi Wu ( $\square$ wuguoyi@163.com )

Shanghai Public Health Clinical Center

\section{Xiaoben Pan}

Hangzhou Normal University Hangzhou School of Medicine

\section{Baohua Wang}

Chinese Center for Disease Control and Prevention

\section{Xiaolei Zhu}

Chinese Center for Disease Control and Prevention

\section{Jing Wu}

Chinese Center for Disease Control and Prevention

\section{Bo Liu}

Sun Yat-Sen University

\section{Research article}

Keywords: Liver metastases, Location, Overall survival, Pancreatic ductal adenocarcinoma, Prognosis, Surveillance, Epidemiology, and End Results

Posted Date: January 14th, 2020

DOI: https://doi.org/10.21203/rs.2.20788/v1

License: (c) (i) This work is licensed under a Creative Commons Attribution 4.0 International License. Read Full License 


\section{Abstract}

\section{Background}

Estimates of the incidence and prognosis of developing liver metastases at the pancreatic ductal adenocarcinoma (PDAC) diagnosis are lacking.

\section{Methods}

In this study, we analyzed the association of liver metastases and the PDAC patients outcome. The risk factors associated with liver metastases in PDAC patients were analyzed using multivariable logistic regression analysis. The overall survival (OS) was estimated using Kaplan-Meier curves and log-rank test. Cox regression was performed to identify factors associated with OS.

Results

Patients with primary PDAC in the tail of the pancreas had a higher incidence of liver metastases (62.2\%) than those with PDAC in the head (28.6\%). Female gender, younger age, primary PDAC in the body or tail of the pancreas, and larger primary PDAC tumor size were positively associated with the occurrence of liver metastases. The median survival of patients with liver metastases was significantly shorter than that of patients without liver metastases. Older age, unmarried status, primary PDAC in the tail of the pancreas, and tumor size $\geq 4 \mathrm{~cm}$ were risk factors for OS in the liver metastases cohort.

Conclusions

Population-based estimates of the incidence and prognosis of PDAC with liver metastases may help decide whether diffusion-weighted magnetic resonance imaging should be performed in patients with primary PDAC in the tail or body of the pancreas. The location of primary PDAC should be considered during the diagnosis and treatment of primary PDAC.

\section{Background}

In 2017, an estimated 55,400 new pancreatic cancer cases were diagnosed in the United States, and 44,330 deaths from pancreatic cancer were reported [1]. Pancreatic ductal adenocarcinoma (PDAC) accounts for up to $95 \%$ of pancreatic cancers. PDAC is predicted to become the second leading cause of cancer-related death in the developed world by 2030 because of its poor overall survival (OS) [2]. PDAC development is associated with few or non-specific symptoms, resulting in a large proportion of patients diagnosed at a late stage with metastatic disease [3]. Primary PDAC located in the body or tail of the pancreas is associated with a poorer prognosis because of its late-stage presentation; however, sociodemographic and clinical predictors of outcome have not been well characterized. The OS of PDAC patients with metastatic disease is considerably poorer than that of patients with localized disease, and the 5-year survival rate for metastatic PDAC is approximately $2 \%$ [4]. 
The sites of PDAC metastases include the lung, brain, and most frequently the liver $[5,6,7]$. There are currently few epidemiological studies reporting on the rate of metastasis in PDAC [8, 9]. Data obtained from multicenter studies have yielded varying results of the association between the primary PDAC location and liver metastases (LM) development $[10,11,12]$. In these few studies analyzed the features and risk factors of LM from PDAC [13, 14], the detailed characteristics and estimates of the prognosis of patients with newly diagnosed PDAC and LM are lacking, possibly because of the limited number of clinical cases reported.

The purpose of this study was to characterize the incidence rate and the associated risk factors of LM at the time of PDAC diagnosis on a population-based level using the Surveillance, Epidemiology, and End Results (SEER) database. In addition, survival estimates were quantified, and clinical and sociodemographic predictors of poor survival were examined in patients with PDAC and LM present at the time of PDAC diagnosis.

\section{Methods}

\section{SEER data}

The SEER Program is a coordinated system of population-based cancer registries that collect incidence and survival data on cases reported from 18 geographic areas, representing almost $28 \%$ of all new cancer diagnoses in the US population per year. With a focus on evaluation of the presence or absence of LM at the time of primary PDAC diagnosis, the data set we extracted was released in November 2017 sub as having systemic malignant disease from 2010 to 2015. According to the policy of The Affiliated Drum Tower Hospital of Nanjing University Medical School, no institutional review board approval was required for this study.

\section{Patient selection and variables}

The study cohort was developed by selecting from all the patients with a precise defined primary cancer site in the pancreas according to the International Classification of Diseases for Oncology, 3rd Edition (ICD-0-3) those with codes C25.0 (head of pancreas), C25.1 (body of pancreas), and C25.2 (tail of pancreas). The patients with ICD-0-3 hist/behav code 8000, 8010, 8140, 8255, 8480, 8481, 8490, 8500, and 8560 were included. A cohort of patients aged 18 years or older at diagnosis, was identified between January 1st, 2010 and December 31st, 2015. Patients with in situ, unstaged carcinoma, or lacking information of carcinoma were not included in the cohort. Patients with unknown presence or absence of LM at diagnosis were excluded. Patients who were diagnosed via autopsy or death certificate, as well as patients of unknown race/ethnicity were also excluded. In total, 42,834 patients were included in the cohort for incidence analysis. Patients without LM and patients with missing or incomplete information concerning survival were subsequently removed, leaving 16,207 patients eligible for survival analysis. 


\section{Statistical analysis}

The patients' demographic and tumor characteristics were summarized using descriptive statistics. Univariable and multivariable logistic regression was used to determine whether variables were associated with the presence of LM at diagnosis. Chi-square test was used to analyze the association between the variables and incidence of presenting LM. Survival curves were obtained using the KaplanMeier method, and differences between the curves were assessed using the log-rank test. Multivariable Cox regression was performed to identify covariates associated with decreased OS using the same variables used in the logistic regression model described herein. The hazard ratios (HRs) with corresponding $95 \%$ confidence intervals (Cls) were used to show the effect of risk factors on OS. Observations were censored if patients were alive at the time of the last follow-up. All statistical analyses were performed using SPSS 23.0 (IBM, Armonk, NY, USA). Statistical significance was set at $p<0.05$.

\section{Results}

\section{Patient characteristics}

The cohort consisted of 42,834 patients with primary PDAC at a specific tumor site in the head, body, or tail of the pancreas. Table 1 shows the baseline characteristics of the patients including sex, race/ethnicity, age at diagnosis, insurance status, marital status, income, primary PDAC location, TNM stage, metastases to liver, and primary PDAC tumor size. Of these patients, 21,302 (49.10\%) had M1 stage, and 16,207 (37.84\%) had developed LM at the time of diagnosis. LM was present in the majority (77.07\%) of PDAC patients with distant metastases. A slightly greater number of patients were men, and most diagnoses were among Non-Hispanic Whites (NHW). The most prevalent age at diagnosis in the cohort was 60-79 years, and most patients were insured. More than half of the patients (54.03\%) were married at the time of diagnosis. The proportion of primary PDAC location was in the head $(65.02 \%)$, body $(17.25 \%)$, and tail (17.73\%) of the pancreas, respectively. The detailed characteristics regarding TNM stage are presented in Table 1. 
Table 1

Characteristics of the study population in SEER

\begin{tabular}{|lll|}
\hline Variable & Total No. & (\%) \\
\hline All PDAC & 42,834 & 100.00 \\
\hline Sex & & \\
\hline Male & 21,925 & 51.19 \\
\hline Female & 20,909 & 48.81 \\
\hline Race & & \\
\hline NHW & 30,048 & 70.15 \\
\hline NHB & 5,205 & 12.15 \\
\hline Hispanic & 4,380 & 10.23 \\
\hline Others & 3,201 & 7.47 \\
\hline Age at diagnosis & & \\
\hline 18-39 & 249 & 0.58 \\
\hline $40-59$ & 8,404 & 19.62 \\
\hline $60-79$ & 24,558 & 57.33 \\
\hline 80 and up & 10,499 & 22.47 \\
\hline Insurance & 9,623 & \\
\hline Insured & & 13.26 \\
\hline Uninsured & $5,706.12$ \\
\hline Others & 36,031 & 54.03 \\
\hline Marital status & 13,122 & \\
\hline Single & 5,681 & \\
\hline Married & & \\
\hline Others & & \\
\hline Income & & \\
\hline Quartile 1 & & \\
\hline & & \\
\hline
\end{tabular}

Abbreviations: NHW, non-Hispanic white; NHB, non-Hispanic black.

a Unknown Income removed from model owing to nonconvergence $(n=1)$. 


\begin{tabular}{|c|c|c|}
\hline Variable & Total No. & $(\%)$ \\
\hline Quartile 2 & 10,333 & 24.12 \\
\hline Quartile 3 & 10,710 & 25.00 \\
\hline Quartile 4 & 11,291 & 26.36 \\
\hline \multicolumn{3}{|l|}{ Location } \\
\hline Head & 27,850 & 65.02 \\
\hline Body & 7,390 & 17.25 \\
\hline Tail & 7,594 & 17.73 \\
\hline \multicolumn{3}{|l|}{ T stage } \\
\hline T1 & 1,667 & 3.89 \\
\hline T2 & 9,955 & 23.24 \\
\hline T3 & 18,379 & 42.91 \\
\hline T4 & 7,774 & 18.15 \\
\hline TX & 5,059 & 11.81 \\
\hline \multicolumn{3}{|l|}{$\mathrm{N}$ stage } \\
\hline NO & 23,229 & 54.23 \\
\hline N1 & 15,595 & 36.41 \\
\hline NX & 4,010 & 9.36 \\
\hline \multicolumn{3}{|l|}{ M stage } \\
\hline MO & 21,802 & 50.90 \\
\hline M1 & 21,032 & 49.10 \\
\hline \multicolumn{3}{|c|}{ Metastases } \\
\hline Liver (yes) & 16,207 & 37.84 \\
\hline Liver (no) & 26,627 & 62.16 \\
\hline \multicolumn{3}{|c|}{ Tumor size (cm) } \\
\hline$\leq 2$ & 3,496 & 8.16 \\
\hline
\end{tabular}

Abbreviations: NHW, non-Hispanic white; NHB, non-Hispanic black.

a Unknown Income removed from model owing to nonconvergence $(n=1)$. 


\begin{tabular}{|lll|}
\hline Variable & Total No. & (\%) \\
\hline $2.1-4$ & 17,851 & 41.67 \\
\hline$\geq 4$ & 16,993 & 39.67 \\
\hline Unknown & 4,494 & 10.49 \\
\hline Abbreviations: NHW, non-Hispanic white; NHB, non-Hispanic black. \\
\hline a Unknown Income removed from model owing to nonconvergence $(n=1)$. \\
\hline
\end{tabular}

\section{Risk factors for developing LM}

Of the 42,834 patients with primary PDAC stratified by age, LM occurred in the age groups $18-39,40-59$, $60-79$, and $\geq 80$ years at frequencies of $45.38 \%, 41.55 \%, 37.97 \%$, and $34.06 \%$, respectively (Fig. $1 \mathrm{~A}$ ). Non-Hispanic Black (NHB) race/ethnicity had a slightly higher incidence $(41.46 \%)$ of LM than NHW $(37.48 \%)$ and Hispanic $(37.72 \%)(p<0.01)$ (Fig. 1B). The cohorts of patients with primary PDAC in the tail $(62.21 \%)$ or body $(47.71 \%)$ of the pancreas had a significantly higher LM incidence than did the cohort with tumors in the head $(28.57 \%)$ of the pancreas $(p<0.01)$ (Fig. 1C). There was a significantly higher incidence rate of LM in the cohort with primary PDAC tumor size larger than $4 \mathrm{~cm}(44.45 \%)$ or unknown primary tumor size $(50.18 \%)$ than primary tumor size $2.1-4 \mathrm{~cm}(24.99 \%)$ or tumor size $<2 \mathrm{~cm}(23.86 \%)$ ( $p$ $<0.01$ ) (Fig. 1D).

Univariate analysis (Table 2) of patients with PDAC showed that primary tumor location at the tail (vs. head; odds ratio (OR), 4.12; $95 \% \mathrm{Cl}, 3.90-4.34 ; \mathrm{p}<0.01$ ) and the body (vs. head; OR, 2.28; $95 \% \mathrm{Cl}, 2.17-$ $2.40 ; \mathrm{P}<0.01)$ of the pancreas were associated with a significantly higher OR of developing LM at diagnosis of PDAC. Greater primary tumor size was significantly associated with a positive OR of LM in both univariate and multivariate analysis. Univariate analysis showed that male sex, younger age, and $\mathrm{NHB}$ race/ethnicity were associated with a higher incidence of LM. Univariate analysis of the roles of T and $\mathrm{N}$ stage showed that patients diagnosed at the T2 or TX stages had a greater likelihood of developing $\mathrm{LM}$ than those at the $\mathrm{T} 1$ stage $(\mathrm{OR}, 2.53 ; 95 \% \mathrm{Cl}, 2.26-2.84 ; \mathrm{P}<0.01$, or $\mathrm{OR}, 6.04 ; 95 \% \mathrm{Cl}$, 5.34-6.82; $\mathrm{P}<0.01$, respectively). Whereas, T3 stage and N1 stage primary PDAC tumors were associated with a lower incidence of LM than T1 stage or N0 stage (OR, 0.84; $95 \% \mathrm{Cl}, 0.75-0.94 ; \mathrm{P}<0.01$, and OR, $0.85 ; 95 \% \mathrm{Cl}, 0.82-0.89 ; \mathrm{P}<0.01$, respectively). Interestingly, on multivariable logistic regression, the $\mathrm{OR}$ of developing LM was $0.69(95 \% \mathrm{Cl}, 0.61-0.79 ; \mathrm{P}<0.01)$ for T4 stage, whereas it was $1.32(95 \% \mathrm{Cl}, 1.17-$ $1.48 ; \mathrm{P}<0.01)$ on univariate regression. 
Table 2

Univariate and multivariate logistic regression analyses of the presence of LM at diagnosis in patients with initial PDAC (diagnosed 2010-2015)

\begin{tabular}{|c|c|c|c|c|}
\hline \multirow[t]{2}{*}{ Variable } & \multicolumn{2}{|l|}{ Univariate } & \multicolumn{2}{|l|}{ Multivariate } \\
\hline & OR (95\%) & P Value & OR (95\%) & P Value \\
\hline \multicolumn{5}{|l|}{ Sex } \\
\hline Male & Ref & & Ref & \\
\hline Female & $0.83(0.80-0.86)$ & $<0.01$ & $0.88(0.84-0.92)$ & $<0.01$ \\
\hline \multicolumn{5}{|l|}{ Race } \\
\hline NHW & Ref & & Ref & \\
\hline $\mathrm{NHB}$ & $1.18(1.11-1.25)$ & $<0.01$ & $1.11(1.04-1.18)$ & $<0.01$ \\
\hline Hispanic & $1.01(0.95-1.08)$ & 0.76 & $0.98(0.91-1.05)$ & 0.55 \\
\hline Others & $0.92(0.82-0.99)$ & 0.03 & $0.89(0.82-0.97)$ & 0.01 \\
\hline \multicolumn{5}{|c|}{ Age at diagnosis } \\
\hline $18-39$ & Ref & & Ref & \\
\hline $40-59$ & $0.86(0.66-1.10)$ & 0.23 & $0.84(0.65-1.10)$ & 0.20 \\
\hline $60-79$ & $0.74(0.51-0.95)$ & 0.02 & $0.75(0.58-0.98)$ & 0.03 \\
\hline 80 and up & $0.62(0.48-0.80)$ & $<0.01$ & $0.67(0.51-0.87)$ & $<0.01$ \\
\hline \multicolumn{5}{|l|}{ Insurance } \\
\hline Insured & Ref & & Ref & \\
\hline Uninsured & $1.31(1.16-1.47)$ & $<0.01$ & $1.15(1.01-1.31)$ & 0.03 \\
\hline Others & $1.15(1.09-1.22)$ & $<0.01$ & $1.10(1.04-1.17)$ & $<0.01$ \\
\hline \multicolumn{5}{|c|}{ Marital status } \\
\hline Married & Ref & & Ref & \\
\hline Single & $1.13(1.07-1.20)$ & $<0.01$ & $1.07(1.01-1.14)$ & 0.03 \\
\hline Others & $0.99(0.95-1.01)$ & 0.77 & $1.07(1.03-1.13)$ & $<0.01$ \\
\hline
\end{tabular}

Abbreviations: NHW, non-Hispanic white; NHB, non-Hispanic black; OR, odds ratio a Unknown Income removed from model owing to nonconvergence $(n=1)$. 


\begin{tabular}{|c|c|c|c|c|}
\hline Variable & Univariate & & Multivariate & \\
\hline Quartile 1 & Ref & & Ref & \\
\hline Quartile 2 & $1.01(0.95-1.07)$ & 0.77 & NA & NA \\
\hline Quartile 3 & $1.05(0.99-1.11)$ & 0.10 & NA & NA \\
\hline Quartile 4 & $0.95(0.90-1.01)$ & 0.08 & NA & NA \\
\hline \multicolumn{5}{|l|}{ Location } \\
\hline Head & Ref & & Ref & \\
\hline Body & $2.28(2.17-2.40)$ & $<0.01$ & $2.23(2.12-2.36)$ & $<0.01$ \\
\hline Tail & $4.12(3.90-4.34)$ & $<0.01$ & $3.82(3.61-4.03)$ & $<0.01$ \\
\hline \multicolumn{5}{|l|}{ T stage } \\
\hline T1 & Ref & & Ref & \\
\hline T2 & $2.53(2.26-2.84)$ & $<0.01$ & $1.59(1.40-1.80)$ & $<0.01$ \\
\hline T3 & $0.84(0.75-0.94)$ & $<0.01$ & $0.53(0.47-0.60)$ & $<0.01$ \\
\hline $\mathrm{T} 4$ & $1.32(1.17-1.48)$ & $<0.01$ & $0.69(0.61-0.79)$ & $<0.01$ \\
\hline TX & $6.04(5.34-6.82)$ & $<0.01$ & $2.73(2.36-3.15)$ & $<0.01$ \\
\hline \multicolumn{5}{|l|}{$\mathrm{N}$ stage } \\
\hline NO & Ref & & Ref & \\
\hline N1 & $0.85(0.82-0.89)$ & $<0.01$ & $0.87(0.83-0.91)$ & $<0.01$ \\
\hline NX & $3.54(3.29-3.80)$ & $<0.01$ & $3.05(2.83-3.29)$ & $<0.01$ \\
\hline \multicolumn{5}{|c|}{ Tumor size (cm) } \\
\hline$\leq 2$ & Ref & & Ref & \\
\hline $2.1-4$ & $1.44(1.32-1.56)$ & $<0.01$ & $1.35(1.24-1.48)$ & $<0.01$ \\
\hline$\geq 4$ & $2.54(2.34-2.76)$ & $<0.01$ & $1.88(1.72-2.05)$ & $<0.01$ \\
\hline Unknown & $3.20(2.90-3.53)$ & $<0.01$ & $2.58(2.31-2.88)$ & $<0.01$ \\
\hline \multicolumn{5}{|c|}{ Abbreviations: NHW, non-Hispanic white; NHB, non-Hispanic black; OR, odds ratic } \\
\hline a Unknow & emoved from moc & owing & onconvergence $(n$ & \\
\hline
\end{tabular}

\section{OS among patients with PDAC and LM at diagnosis}


The median OS for PDAC patients without LM was 9 months (95\% Cl: 8.81-9.19), whereas that in the cohort with PDAC and LM at diagnosis was 2 months (95\% Cl: 1.92-2.08). The presence of LM at initial diagnosis was associated with shorter survival time than that of patients presenting without baseline liver involvement. The median survival among all PDAC patients in the study group was longest in patients with a primary tumor in the head of the pancreas ( 7 months, $95 \% \mathrm{Cl}: 6.84-7.16)$ and shorter in those with a primary tumor in the body of the pancreas ( 5 months, $95 \% \mathrm{Cl}: 4.75-5.25$ ). Patients with a primary PDAC tumor in the tail of pancreas had the shortest median survival (3 months, 95\% Cl: 2.843.16). In PDAC patients with LM sub-cohort, those with a primary tumor in the head of the pancreas had the longest median survival ( 3 months, $95 \% \mathrm{Cl}: 2.89-3.11$ ), whereas those with a primary tumor in the body or tail of the pancreas had a slightly shorter median survival (2 months, 95\% Cl: 1.82-2.19; $\mathrm{P}<0.01$, and 2 months, $95 \% \mathrm{Cl}: 1.91-2.09 ; \mathrm{P}<0.01$, respectively). Figure 2 shows the $0 \mathrm{~S}$ estimates (Fig. $2 \mathrm{~A}$ ), the OS estimates stratified by primary tumor location (Fig. 2B), and the OS estimates stratified by extent of identified LM at diagnosis (Fig. 2C). The median survival did not differ significantly according to tumor location among the three primary PDAC-with-LM groups (Fig. 2D).

\section{Prognostic factors for OS in PDAC patients with LM}

On multivariable Cox regression analysis (Table 3 ) of OS among PDAC patients with LM at diagnosis, female gender (vs. male gender; $\mathrm{HR}, 0.92 ; 95 \% \mathrm{Cl}, 0.89-0.95 ; \mathrm{P}<0.01$ ) was associated with increased OS. However, other factors including age $40-59$ years (vs. age $18-39$ years; $\mathrm{HR}, 1.35 ; 95 \% \mathrm{Cl}, 1.10-1.67 ; \mathrm{P}<$ 0.01 ), age $60-79$ years (vs. age $18-39$ years; $\mathrm{HR}, 1.81 ; 95 \% \mathrm{Cl}, 1.47-2.23 ; \mathrm{P}<0.01$ ), age $>80$ years (vs. age 18-39 years; HR, 2.98; 95\% Cl, 2.42-3.68; $\mathrm{P}<0.01$ ), uninsured status (vs. insured status ; HR, 1.25 , 95\% Cl, 1.14-1.38; $\mathrm{P}<0.01$ ), primary PDAC location at the body (vs. head; $\mathrm{HR}, 1.06,95 \% \mathrm{Cl}, 1.02-1.11 ; \mathrm{P}$ $<0.01$ ), at the tail (vs. head; $\mathrm{HR}, 1.16,95 \% \mathrm{Cl}, 1.12-1.20 ; \mathrm{P}<0.01$ ) of the pancreas, and primary tumor size $\geq 4 \mathrm{~cm}$ (vs. size $<2 \mathrm{~cm} ; \mathrm{HR}, 1.16,95 \% \mathrm{Cl}, 1.07-1.25 ; \mathrm{P}<0.01$ ) were significantly associated with decreased OS. 
Table 3

Multivariable Cox Regression for OS Among Patients with LM

\begin{tabular}{|c|c|c|c|c|c|c|}
\hline \multirow{2}{*}{ Variable } & \multicolumn{3}{|c|}{ All PDAC patients } & \multicolumn{3}{|c|}{ PDAC patients with LM } \\
\hline & $\begin{array}{l}\text { Patients, } \\
\text { No. }\end{array}$ & $\begin{array}{l}\text { Hazard Ratio } \\
(95 \% \mathrm{Cl})\end{array}$ & $\begin{array}{l}P \\
\text { Value }\end{array}$ & $\begin{array}{l}\text { Patients, } \\
\text { No. }\end{array}$ & $\begin{array}{l}\text { Hazard Ratio } \\
(95 \% \mathrm{Cl})\end{array}$ & $\begin{array}{l}\mathrm{P} \\
\text { Value }\end{array}$ \\
\hline Total & 42,834 & & & 16,207 & & \\
\hline \multicolumn{7}{|l|}{ Sex } \\
\hline Male & 21,925 & Ref & & 8,762 & Ref & \\
\hline Female & 20,909 & $0.91(0.89-0.93)$ & $\begin{array}{l}<.01 \\
0.01\end{array}$ & 7,445 & $0.92(0.89-0.95)$ & $<0.01$ \\
\hline \multicolumn{7}{|l|}{ Race } \\
\hline NHW & 30,048 & Ref & & 11,261 & Ref & \\
\hline $\mathrm{NHB}$ & 5,205 & $1.07(1.04-1.11)$ & $\begin{array}{l}< \\
0.01\end{array}$ & 2,158 & NA & NA \\
\hline Hispanic & 4,380 & $1.03(0.99-1.07)$ & 0.14 & 1,652 & NA & NA \\
\hline Other & 3,201 & $0.99(0.95-1.03)$ & 0.57 & 1,136 & NA & NA \\
\hline \multicolumn{7}{|l|}{ Age } \\
\hline $18-39$ & 249 & Ref & & 113 & Ref & \\
\hline $40-59$ & 8,404 & $1.32(1.13-1.53)$ & $\begin{array}{l}<.01 \\
0.01\end{array}$ & 3,492 & $1.35(1.10-1.67)$ & 0.01 \\
\hline $60-79$ & 24,558 & $1.68(1.44-1.95)$ & $\begin{array}{l}<.01 \\
0.01\end{array}$ & 9,324 & $1.81(1.47-2.23)$ & $<0.01$ \\
\hline 80 up & 9,623 & $2.81(2.41-3.27)$ & $\begin{array}{l}< \\
0.01\end{array}$ & 3,278 & $2.98(2.42-3.68)$ & $<0.01$ \\
\hline \multicolumn{7}{|l|}{ Insurance } \\
\hline Insured & 28,793 & Ref & & 10,371 & Ref & \\
\hline Uninsured & 1,122 & $1.22(1.17-1.25)$ & $\begin{array}{l}< \\
0.01\end{array}$ & 490 & $1.25(1.14-1.38)$ & $<0.01$ \\
\hline Others & 12,919 & $1.26(1.23-1.30)$ & $\begin{array}{l}< \\
0.01\end{array}$ & 4,986 & $1.22(1.19-1.29)$ & $<0.01$ \\
\hline \multicolumn{7}{|l|}{ Marital } \\
\hline Abbreviatic & $\mathrm{HW}$, non-His & nic white; NHB, n & Hispanic & black. & & \\
\hline
\end{tabular}




\begin{tabular}{|c|c|c|c|c|c|c|}
\hline \multirow[t]{2}{*}{ Variable } & \multicolumn{3}{|c|}{ All PDAC patients } & \multicolumn{3}{|c|}{ PDAC patients with LM } \\
\hline & $\begin{array}{l}\text { Patients, } \\
\text { No. }\end{array}$ & $\begin{array}{l}\text { Hazard Ratio } \\
(95 \% \mathrm{Cl})\end{array}$ & $\begin{array}{l}\mathrm{P} \\
\text { Value }\end{array}$ & $\begin{array}{l}\text { Patients, } \\
\text { No. }\end{array}$ & $\begin{array}{l}\text { Hazard Ratio } \\
(95 \% \mathrm{Cl})\end{array}$ & $\begin{array}{l}\mathrm{P} \\
\text { Value }\end{array}$ \\
\hline Married & 23,143 & Ref & & 8,679 & Ref & \\
\hline Single & 5,706 & $1.21(1.17-1.25)$ & $\begin{array}{l}< \\
0.01\end{array}$ & 2,305 & $1.20(1.14-1.26)$ & 0.09 \\
\hline Other & 13,985 & $1.23(1.20-1.26)$ & $\begin{array}{l}< \\
0.01\end{array}$ & 5,223 & $1.24(1.19-1.29)$ & $<0.01$ \\
\hline \multicolumn{7}{|l|}{ Income ${ }^{a}$} \\
\hline Q1 & 10,499 & Ref & & 4,107 & Ref & \\
\hline Q2 & 10,333 & $0.93(0.90-0.96)$ & $\begin{array}{l}< \\
0.01\end{array}$ & 4,042 & $0.96(0.92-1.01)$ & 0.09 \\
\hline Q3 & 10,710 & $0.88(0.85-0.91)$ & $\begin{array}{l}< \\
0.01\end{array}$ & 4,167 & $0.89(0.85-0.93)$ & $<0.01$ \\
\hline Q4 & 11,291 & $0.83(0.81-0.86)$ & $\begin{array}{l}<.01 \\
0.01\end{array}$ & 3,891 & $0.85(0.81-0.89)$ & $<0.01$ \\
\hline \multicolumn{7}{|l|}{ Location } \\
\hline Head & 27,850 & Ref & & 7,957 & Ref & \\
\hline Body & 7,390 & $1.18(1.15-1.21)$ & $\begin{array}{l}< \\
0.01\end{array}$ & 3,526 & $1.06(1.02-1.11)$ & 0.01 \\
\hline Tail & 7,594 & $1.36(1.32-1.40)$ & $\begin{array}{l}< \\
0.01\end{array}$ & 4,724 & $1.16(1.12-1.20)$ & $<0.01$ \\
\hline \multicolumn{7}{|l|}{ T stage } \\
\hline T1 & 1,667 & Ref & & 471 & Ref & \\
\hline T2 & 9,955 & $1.39(1.30-1.48)$ & $\begin{array}{l}< \\
0.01\end{array}$ & 4,970 & $0.91(0.81-1.01)$ & 0.06 \\
\hline T3 & 18,379 & $0.93(0.88-1.00)$ & 0.03 & 4,551 & $0.77(0.69-0.86)$ & $<0.01$ \\
\hline T4 & 7,774 & $1.21(1.13-1.30)$ & $\begin{array}{l}< \\
0.01\end{array}$ & 2,654 & $0.80(0.72-0.90)$ & $<0.01$ \\
\hline TX & 5,059 & $1.66(1.54-1.78)$ & $\begin{array}{l}<.01 \\
0.01\end{array}$ & 3,561 & $0.99(0.82-1.03)$ & $<0.01$ \\
\hline
\end{tabular}

Abbreviation: NHW, non-Hispanic white; NHB, non-Hispanic black.

a Unknown Income removed from model owing to nonconvergence $(n=1)$. 


\begin{tabular}{|c|c|c|c|c|c|c|}
\hline \multirow[t]{2}{*}{ Variable } & \multicolumn{3}{|c|}{ All PDAC patients } & \multicolumn{3}{|c|}{ PDAC patients with LM } \\
\hline & $\begin{array}{l}\text { Patients, } \\
\text { No. }\end{array}$ & $\begin{array}{l}\text { Hazard Ratio } \\
(95 \% \mathrm{Cl})\end{array}$ & $\begin{array}{l}\mathrm{P} \\
\text { Value }\end{array}$ & $\begin{array}{l}\text { Patients, } \\
\text { No. }\end{array}$ & $\begin{array}{l}\text { Hazard Ratio } \\
(95 \% \mathrm{Cl})\end{array}$ & $\begin{array}{l}\mathrm{P} \\
\text { Value }\end{array}$ \\
\hline \multicolumn{7}{|l|}{$\mathrm{N}$ stage } \\
\hline NO & 23,229 & Ref & & 8,434 & Ref & \\
\hline N1 & 15,595 & $0.90(0.88-0.92)$ & $\begin{array}{l}< \\
0.01\end{array}$ & 5,093 & $1.02(0.98-1.06)$ & 0.36 \\
\hline NX & 4,010 & $1.51(1.45-1.56)$ & $\begin{array}{l}< \\
0.01\end{array}$ & 2,680 & $1.13(1.08-1.18)$ & $<0.01$ \\
\hline \multicolumn{7}{|l|}{$\begin{array}{l}\text { Tumor size } \\
\text { (cm) }\end{array}$} \\
\hline$\leq 2$ & 3,496 & Ref & & 834 & Ref & \\
\hline $2.1-4$ & 17,851 & $1.31(1.26-1.37)$ & $\begin{array}{l}< \\
0.01\end{array}$ & 5,561 & $1.01(0.94-1.10)$ & 0.74 \\
\hline$\geq 4$ & 16,993 & $1.64(1.56-1.71)$ & $\begin{array}{l}<.01 \\
0.01\end{array}$ & 7,554 & $1.16(1.07-1.25)$ & $<0.01$ \\
\hline Unknown & 4,494 & $1.99(1.88-2.11)$ & $\begin{array}{l}< \\
0.01\end{array}$ & 2,255 & $1.22(1.12-1.32)$ & $<0.01$ \\
\hline \multicolumn{7}{|c|}{ Abbreviation: NHW, non-Hispanic white; NHB, non-Hispanic black. } \\
\hline
\end{tabular}

NHB was associated with poorer OS than NHW among all PDAC patients cohort but not among PDAC patients with LM sub-cohort. Although single (vs. married) was significantly associated with poor outcome in all PDAC patients cohort, the association was not significant in PDAC patients with LM subcohort. Higher T and N stage were not associated with worse OS in the two cohorts.

\section{Discussion}

The poor survival of patients with PDAC is largely due to the absence of methods for early diagnosis, and the development of metastases [15]. In cases of aggressive PDAC, metastasis is frequently present at the time of primary diagnosis, occurring in the peritoneal cavity, pleura, lung, and bone, although the most common site of metastases is the liver [16]. Improving our knowledge of the incidence and survival characteristics of PDAC patients with LM, as well as the relative risk and prognostic factors, is critical for the diagnosis and treatment planning for PDAC patients. However, few epidemiological studies have been conducted on the features of metastases in PDAC to date [8, 9]. The present US-population based study provides an unbiased and detailed analysis of the incidence of $L M$ among patients with newly diagnosed PDAC and the subsequent survival of such patients. 
To the best of our knowledge, the present study is currently the largest report on such issues to use population-based data sets. We found that the risk factors for LM occurrence at PDAC diagnosis were male gender, NHB (vs. NHW) race/ethnicity, younger age, primary PDAC located at the tail or body (vs. head) of the pancreas, and larger tumor size. Among the entire cohort, male (vs. female) patients, NHB (vs. NHW) race/ethnicity, uninsured (vs. insured) status, single (vs. married) status, lower (vs. higher) income, larger (vs. smaller) tumor size and primary PDAC located at the tail or body (vs. head) of the pancreas were associated with a significantly greater HR of worse OS; however, the association of NHB race/ethnicity with poorer OS or the association of single status with poorer OS was not observed in the cohort of PDAC patients with LM. The HR of OS was not associated with poorer T stage or $\mathrm{N}$ stage at diagnosis as defined by the 7th edition of AJCC Cancer Staging system in all PDAC patients cohort or PDAC patients with LM sub-cohort. These data are not in agreement with the conclusions reported by other studies regarding general OS trends [17].

The newly published French clinical practice guidelines for the diagnosis, treatment, and follow-up of pancreatic cancer indicated that clinical presentation depends mainly on the primary PDAC location and the stage at diagnosis [18]. Fewer than $10 \%$ of patients diagnosed with PDAC are potentially curable through resection, and patients presenting with metastatic disease at diagnosis are not suitable for surgical resection [19]. Multidetector Computed Tomography (MDCT) is normally performed using thin sections and intravenous contrast injection after the diagnosis of PDAC. It is used for the evaluation of tumor resectablility and metastases. Another sensitive and specific alternative imaging modality is diffusion-weighted (DW) magnetic resonance imaging (-MRI), which allows for the characterization of barely visible isoattenuating PDAC and small or indeterminate LM on MDCT. Performing liver DW-MRI before laparotomy is useful for excluding infra-centimetric LM and by subsequently avoiding futile surgery [20]. However, its clinical use is limited because of high cost and poor accessibility. Therefore, it is important to define inclusion and exclusion criteria for PDAC patients regarding the need for DW-MRI scanning. Our findings suggest that patients with primary PDAC at the body or tail of the pancreas and those with a primary tumor size $\geq 4 \mathrm{~cm}$ should receive DW-MRI including precise scanning of the liver.

Dong et al. reported on the incidence rate of PDAC with synchronous LM between 2004 and 2014 in a multicenter cohort study conducted in Shanghai, China [14]. In that study, larger tumor size, primary tumor location at the head/neck of the pancreas, and diameter $\geq 2 \mathrm{~cm}$ were significantly associated with the risk of synchronous LM. Opposite results were reported by Felice et al., who showed that PDAC location in the body and tail of the pancreas was associated with a larger tumor size and a greater incidence of metastatic disease in a population-based study using Netherlands Cancer Registry data [13]. Apart from these contradictory results, there are no studies reporting on the pattern and risk factors for the incidence of and survival from LM in PDAC patients. In contrast to most of the published literature on this topic, our work focused on patients presenting with de novo metastatic PDAC. Our results confirm and extend previous work describing the interaction between tumor location and the risk of LM among patients initially presenting with primary PDAC. 
We also showed that the node and metastases (TNM) classification of the AJCC 7th edition is not suitable for the prognostic evaluation of PDAC patients presenting with LM. However, tumor size was identified as a good prognostic factor for predicting the HRs of the whole PDAC cohort and the LM subcohort. Thus, the new 8th edition of the AJCC TNM classification, which incorporates changes to the T and $\mathrm{N}$ classifications, including tumor size, is superior to the 7th edition for predicting the survival outcome of pancreatic cancer patients [21]. In PDAC patients with LM, male gender, old age, single or other unmarried status, primary PDAC location at the tail of the pancreas, and tumor size $\geq 4 \mathrm{~cm}$ need to be considered as risk factors for overall mortality. More importantly, we found that the presence of LM at initial diagnosis was associated with a shorter survival time than that of patients presenting with de novo metastatic disease without baseline liver involvement.

\section{Limitations}

The present study had several limitations. Firstly, the data available were limited to the presence or absence of LM at the time of primary PDAC diagnosis. The SEER database does not provide information on tumor recurrence or subsequent sites of disease, and we were unable to describe metachronous LM in PDAC patients. Secondly, because routine diagnostic methods in PDAC patients do not include DW-MRI for the detection of LM, many patients presenting with liver micrometastases at diagnosis may not have been identified by other examinations [22]. It is therefore possible that we underestimated the actual rate of LM in patients with newly diagnosed PDAC. In addition, the threshold for obtaining imaging of the liver may have varied among different hospitals and doctors. Thirdly, we cannot comment on the treatment received by patients with $L M$ because such information is not recorded in the SEER database. Such drawbacks are inherent to any retrospective, population-based study and may raise concerns about the general applicability of the findings. However, the size of the present study, which we believe to be the largest to date, compensates to a great extent, and the study provides a comprehensive epidemiological picture of primary PDAC patients with LM.

\section{Conclusions}

The present study provides insight into the epidemiology of LM in patients with newly diagnosed PDAC in the United States. The findings of our study support the utility of performing DW-MRI of the abdomen with particular focus on the liver in patients at high risk of LM, including those with primary PDAC at the tail or body of the pancreas and those with larger primary tumor size. Older unmarried patients with the primary tumor location at the body or tail of the pancreas, and a primary tumor size $\geq 4 \mathrm{~cm}$ may have a negative impact on the OS of PDAC patients with LM.

\section{List Of Abbreviations}

AJCC - American Joint Committee on Cancer

$\mathrm{Cl}$ - Confidence Interval 
HR - Hazard Ratio

ICD-0-3 - International Classification of Diseases for Oncology, 3rd Edition

OR - Odds Ratio

OS - Overall Survival

PDAC - Pancreatic Ductal Adenocarcinoma

SEER - Surveillance, Epidemiology, and End Results

TNM - Tumor-Node-Metastasis

\section{Declarations}

\section{Ethics approval and consent to participate}

Not applicable

\section{Consent for publication}

Not applicable

\section{Availability of data and materials}

The datasets generated and/or analysed during the current study are available in the Surveillance, Epidemiology, and End Results (SEER) Program repository, [https://seer.cancer.gov]

\section{Competing interests}

The authors declare that they have no competing interests

\section{Funding}

This research was funded by the National Key Research and Development Program of China (grant no. 2016YFC1302603)

\section{Authors' contributions}

Drs GW and JW, had full access to all of the data in the study and take responsibility for the integrity of the data and the accuracy of the data analysis.

GW, JW, XP, and BW generated the study concept and design. GW, BW, and XZ worked on the acquisition, analysis, or interpretation of data. GW and JW worked on the drafting of the manuscript. XP, BL, and JW 
worked on the critical revision of the manuscript for important intellectual content. GW, JW, and BL performed the statistical analysis. All authors read and approved the final manuscript.

Acknowledgements

Not applicable

\section{References}

1. Siegel RL, Miller KD, Jemal A: Cancer statistics, 2018. CA Cancer J Clin 2018, 68:7-30.

2. Rahib L, Smith BD, Aizenberg R, Rosenzweig AB, Fleshman JM, Matrisian LM: Projecting cancer incidence and deaths to 2030: the unexpected burden of thyroid, liver, and pancreas cancers in the United States. Cancer Res 2014, 74:2913-2921.

3. Donahue TR, Reber HA: Surgical management of pancreatic cancer-pancreaticoduodenectomy. Semin Oncol 2015, 42:98-109.

4. Mohammad AA: Advanced pancreatic cancer: The standard of care and new opportunities. Oncol Rev 2018, 12:

5. Mohammad AA: Advanced pancreatic cancer: The standard of care and new opportunities. Oncol Rev 2018, 12:

6. Jordan EJ, Lowery MA, Basturk O, Allen PJ, Yu KH, Tabar V, Beal K, Reidy DL, Yamada Y, Janjigian Y, et al: Brain Metastases in Pancreatic Ductal Adenocarcinoma: Assessment of Molecular GenotypePhenotype Features-An Entity With an Increasing Incidence? Clin Colorectal Cancer 2018, 17:e315e321.

7. Andreou A, Knitter S, Klein F, Malinka T, Schmelzle M, Struecker B, Schmuck RB, Noltsch AR, Lee D, Pelzer $U$, et al: The role of hepatectomy for synchronous liver metastases from pancreatic adenocarcinoma. Surg Oncol 2018, 27:688-694.

8. Wiltberger G, Bucher JN, Krenzien F, Benzing C, Atanasov G, Schmelzle M, Hau HM, Bartels M: Extended resection in pancreatic metastases: feasibility, frequency, and long-term outcome: a retrospective analysis. Bmc Surg 2015, 15:

9. Bouglouga O, Lawson-Ananissoh LM, Bagny A, Kaaga L, Redah D: [Pancreatic cancer: Epidemiological, clinical, and management aspects in the department of hepatogastroenterology at the Lome Campus teaching hospital (Togo)]. Med Sante Trop 2015, 25:323-326.

10. Bouglouga O, Lawson-Ananissoh LM, Bagny A, Kaaga L, Redah D: [Pancreatic cancer:

Epidemiological, clinical, and management aspects in the department of hepatogastroenterology at the Lome Campus teaching hospital (Togo)]. Med Sante Trop 2015, 25:323-326.

11. Ambrosetti MC, Zamboni GA, Mucelli RP: Distribution of liver metastases based on the site of primary pancreatic carcinoma. Eur Radiol 2016, 26:306-310.

12. Mackay TM, van Erning FN, van der Geest L, de Groot J, Haj MN, Lemmens VE, van Laarhoven HW, Besselink MG, Wilmink JW: Association between primary origin (head, body and tail) of metastasised 
pancreatic ductal adenocarcinoma and oncologic outcome: A population-based analysis. Eur J Cancer 2019, 106:99-105.

13. van Erning FN, Mackay TM, van der Geest L, Groot KB, van Laarhoven $H$, Bonsing BA, Wilmink JW, van Santvoort HC, de Vos-Geelen J, van Eijck C, et al: Association of the location of pancreatic ductal adenocarcinoma (head, body, tail) with tumor stage, treatment, and survival: a population-based analysis. Acta Oncol 2018, 57:1655-1662.

14. S D, L W, B GY, F YH, H SX, Q MZ, Hao C, W CQ, S LZ: Risk factors of liver metastasis from advanced pancreatic adenocarcinoma: a large multicenter cohort study. World J Surg Oncol 2017, 15:

15. Ryan DP, Hong TS, Bardeesy N: Pancreatic adenocarcinoma. N Engl J Med 2014, 371:1039-1049.

16. Yachida S, lacobuzio-Donahue CA: The pathology and genetics of metastatic pancreatic cancer. Arch Pathol Lab Med 2009, 133:413-422.

17. Oweira H, Petrausch U, Helbling D, Schmidt J, Mannhart M, Mehrabi A, Schob O, Giryes A, Decker M, Abdel-Rahman O: Prognostic value of site-specific metastases in pancreatic adenocarcinoma: A Surveillance Epidemiology and End Results database analysis. World J Gastroentero/ 2017, 23:18721880.

18. Oweira H, Petrausch U, Helbling D, Schmidt J, Mannhart M, Mehrabi A, Schob O, Giryes A, Decker M, Abdel-Rahman O: Prognostic value of site-specific metastases in pancreatic adenocarcinoma: A Surveillance Epidemiology and End Results database analysis. World J Gastroentero/ 2017, 23:18721880.

19. Balaban EP, Mangu PB, Khorana AA, Shah MA, Mukherjee S, Crane CH, Javle MM, Eads JR, Allen P, Ko AH, et al: Locally Advanced, Unresectable Pancreatic Cancer: American Society of Clinical Oncology Clinical Practice Guideline. J Clin Oncol 2016, 34:2654-2668.

20. Marion-Audibert AM, Vullierme MP, Ronot M, Mabrut JY, Sauvanet A, Zins M, Cuilleron M, Sa-Cunha A, Levy P, Rode A: Routine MRI With DWI Sequences to Detect Liver Metastases in Patients With Potentially Resectable Pancreatic Ductal Carcinoma and Normal Liver CT: A Prospective Multicenter Study. AJR Am J Roentgenol 2018, 211:W217-W225.

21. Cong L, Liu Q, Zhang R, Cui M, Zhang X, Gao X, Guo J, Dai M, Zhang T, Liao Q, Zhao Y: Tumor size classification of the 8 (th) edition of TNM staging system is superior to that of the 7 (th) edition in predicting the survival outcome of pancreatic cancer patients after radical resection and adjuvant chemotherapy. Sci Rep 2018, 8:10383.

22. Katada T, Hashidate H, Yokoyama N, Sudo N, Mitsuma K, Otani T: Initial Features of Hepatic Metastases From Pancreatic Cancer: Histological and Radiolographical Appraisal of Hepatic Micrometastases Detected by Real-Time Fluorescent Imaging. Pancreas 2017, 46:1196-1201.

\section{Figures}


A

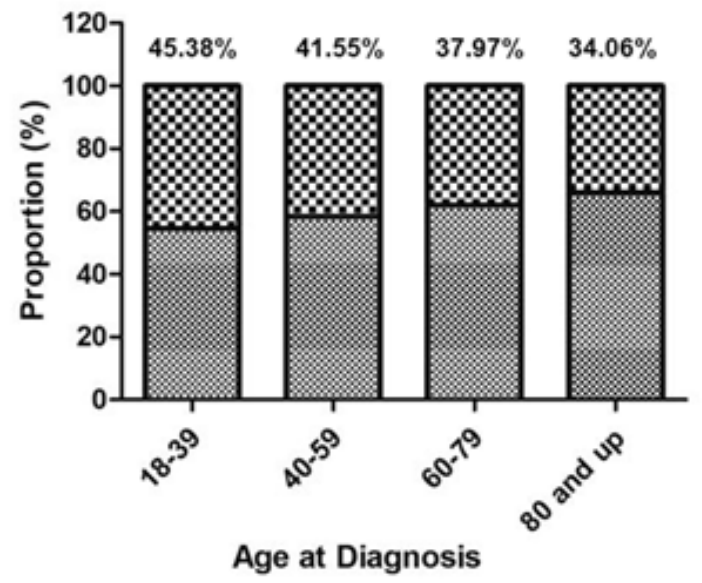

C

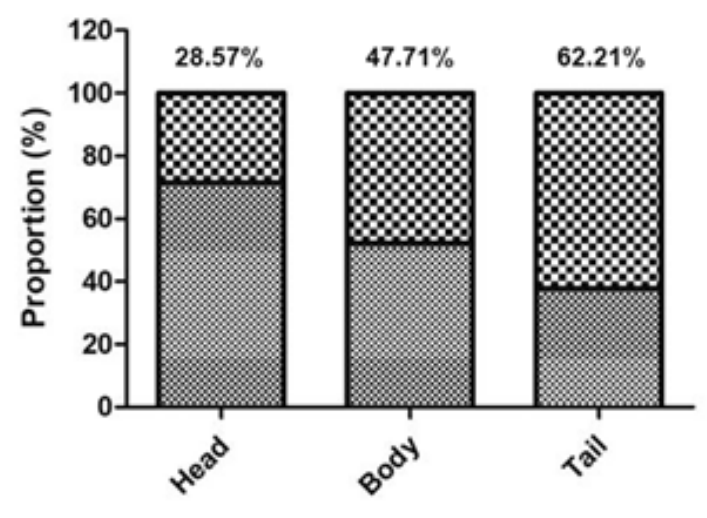

Primary PDAC Location
B

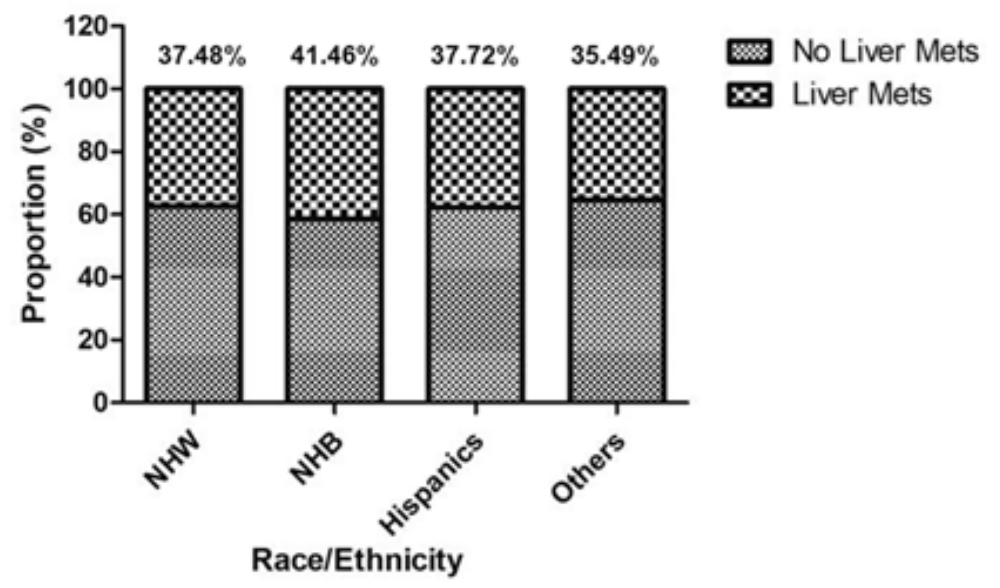

D

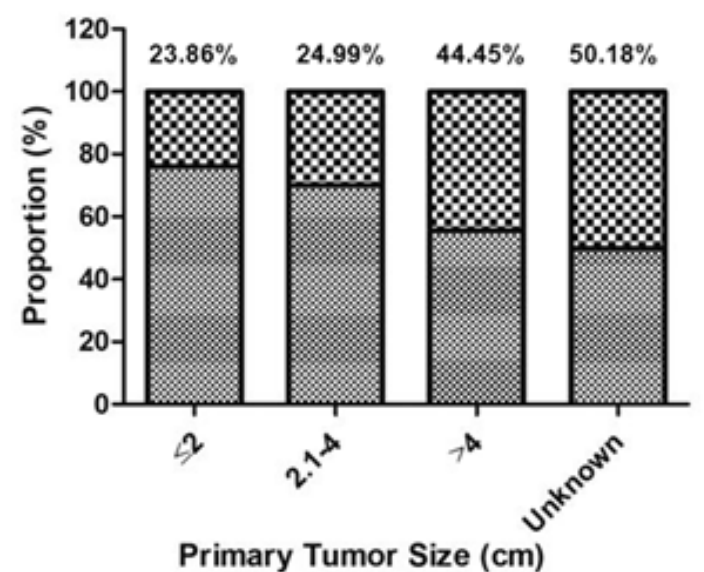

Figure 1

Rate of incidence of developing LM (\%) among patients with primary PDAC stratified by age (A), race/ethnicity (B), primary PDAC location (C), and primary tumor size (D). 
A

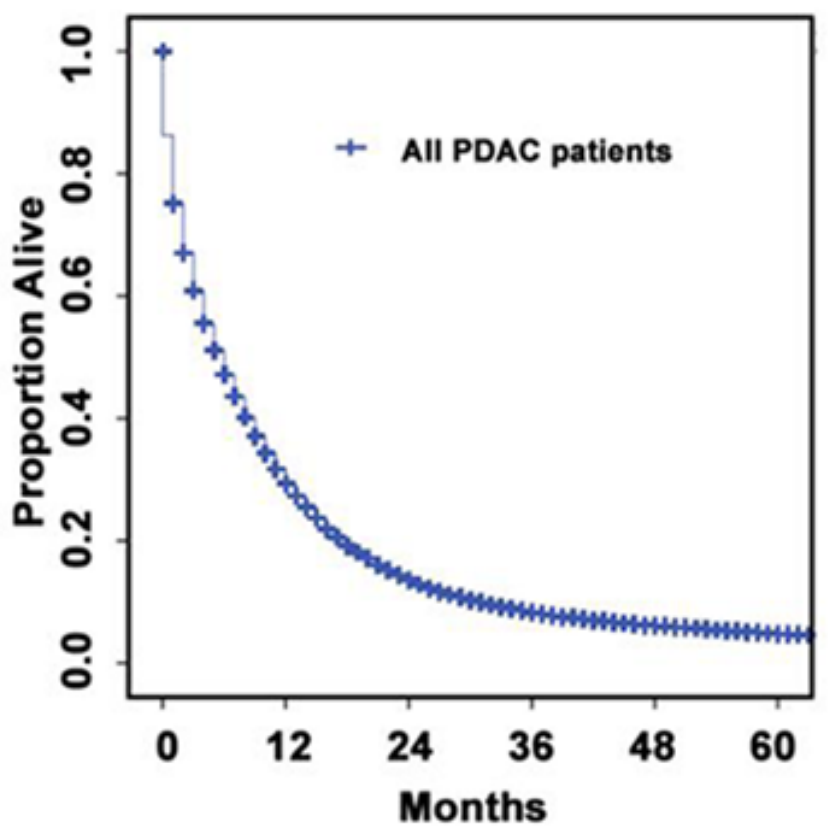

C

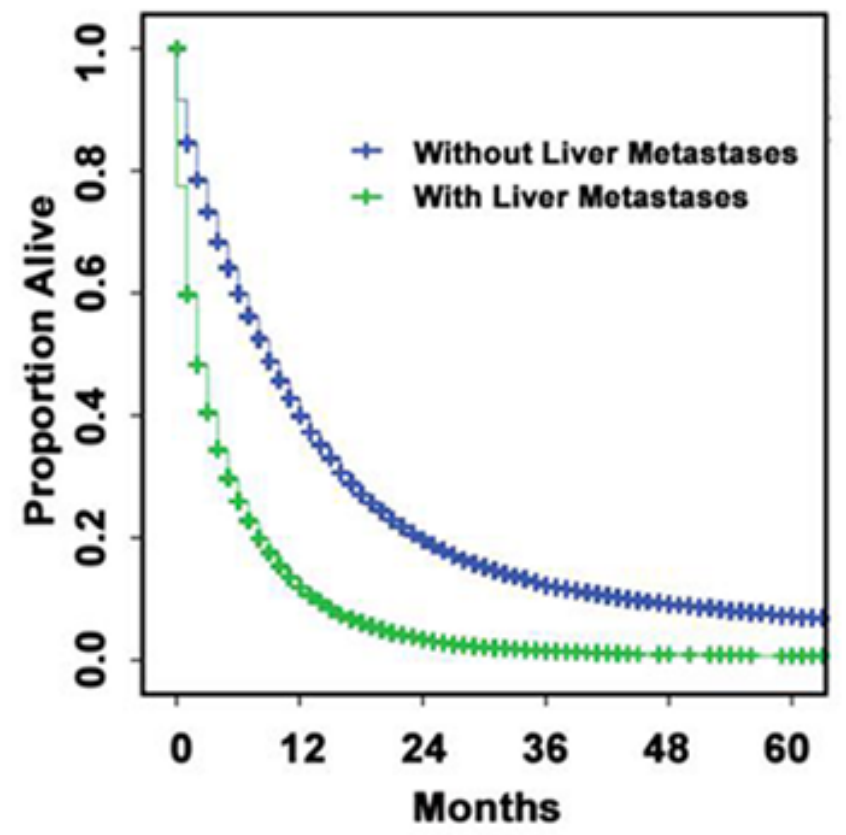

B

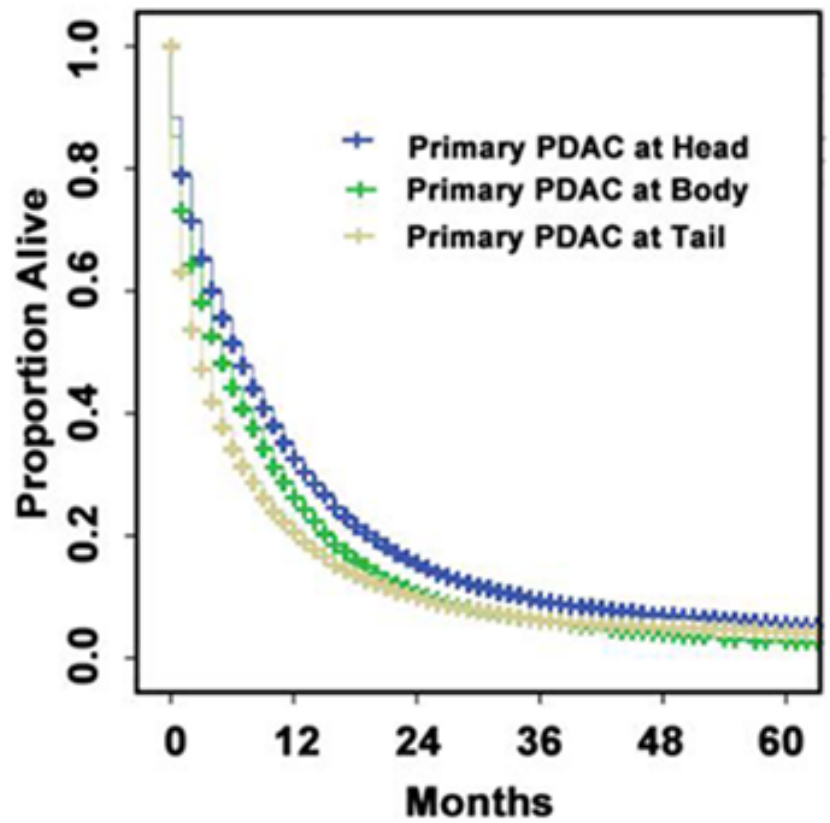

D

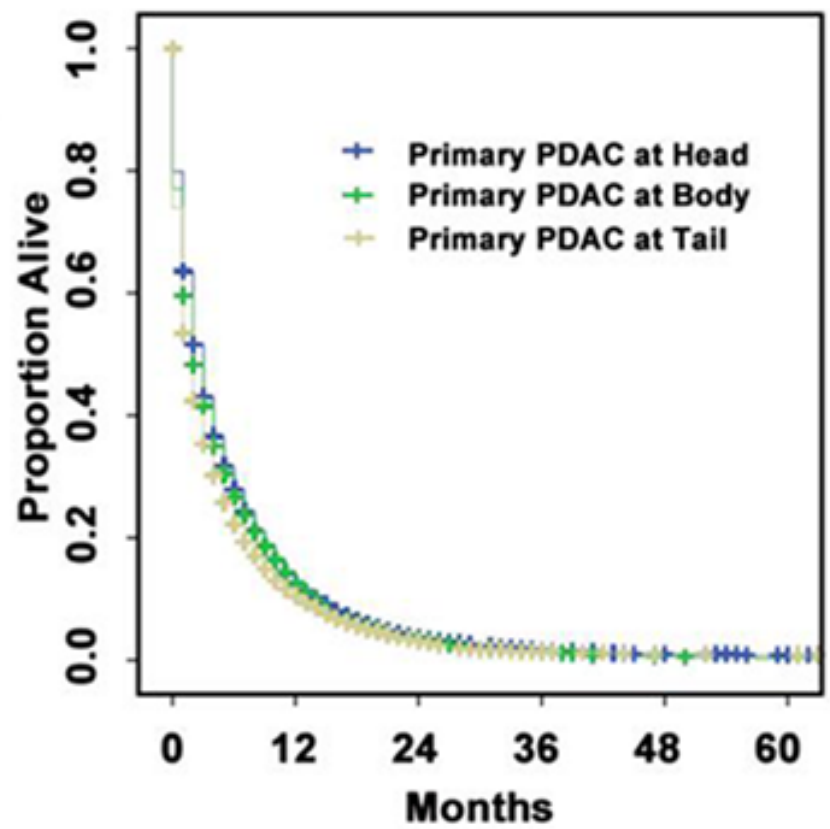

Figure 2

Kaplan-Meier analysis of OS in patients diagnosed with PDAC (A, Overall), stratified by primary PDAC location (B), presence or absence of LM (C), and PDAC patients with LM stratified by primary PDAC location (D). 